\title{
Steryl glucosides from banana plant Musa acuminata Colla var cavendish
}

\author{
L. Oliveira ${ }^{\mathrm{a}, \mathrm{b}}$, C.S.R. Freire ${ }^{\mathrm{c}}$, A.J.D. Silvestre ${ }^{\mathrm{c}, *}$, N. Cordeiro $^{\mathrm{a}, \mathrm{b}}$, \\ I.C. Torres ${ }^{\mathrm{a}, \mathrm{b}}$, D. Evtuguin ${ }^{\mathrm{c}}$ \\ a Departamento de Química, Universidade da Madeira, 9000-390 Funchal, Portugal \\ b Centro de Estudos da Macaronésia, Universidade da Madeira, 9000-390 Funchal, Portugal

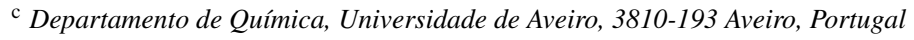 \\ Received 6 June 2004; accepted 6 October 2004
}

\begin{abstract}
The chemical composition of the dichloromethane extracts of several vegetal fractions of banana plant, Musa acuminata Colla var cavendish have been studied by GC-MS. Several bioactive steryl glucosides, namely campesteryl 3- $\beta$-D-glucopyranoside, stigmasteryl 3- $\beta$-D-glucopyranoside and sitosteryl 3- $\beta$-D-glucopyranoside were identified as the major components of the extracts, accounting for $838.4-1824.3 \mathrm{mg} / \mathrm{kg}$ of the plant fractions dry weight. The high abundance of these compounds might be an important contribution to the valorization of banana plant agricultural residues.
\end{abstract}

(C) 2004 Elsevier B.V. All rights reserved.

Keywords: Musa acuminata Colla; Agricultural residues; Extractives; Steryl glucosides; GC-MS

\section{Introduction}

The banana plant is a very important crop in the Madeira Island economy. The sub-tropical climatic conditions of Madeira Island allowed the successful introduction of this crop in the middle of the sixteenth century. The banana plant is spread all over the island, but it is more abundant on the south coast, on areas up to $300 \mathrm{~m}$ above the sea level (Nogueira et al., 2003).

\footnotetext{
* Corresponding author. Tel.: +351234370 711; fax: +35134370084.

E-mail address: armsil@dq.ua.pt (A.J.D. Silvestre).
}

According to official statistics, the banana plantations produce annually $c a$. 30.000 tons of fruit, which represent a substantial economic profit to this region. After the harvesting of the single bunch of bananas, great amounts of agricultural residues are produced. Pseudostems and foliage, are usually left in the soil plantation to be used as organic material. However, those fractions, together with rachis, a by-product of banana processing, could represent an important renewable source of fine chemicals and fibres.

Among the cultivated species, "Dwarf Cavendish" (Musa acuminata Colla var cavendish) is nowadays 
the economically most important cultivar in terms of cultivated area as well as production volume in Madeira Island (ca. 50-60\% of the total banana production). The agricultural residues produced on the plantations reach around 15.000 ton/year.

The development of new applications for the banana plant residues would represent an important contribution to increase the economical importance of banana plantations. The detailed study on the chemical composition of the different morphological regions of "Dwarf Cavendish" is an important step to achieve such objective. In this context, some studies concerning the chemical composition of "Dwarf Cavendish" (Cordeiro et al., 2004; Faria et al., 2002; Oliveira et al., 2002) have been published. The high content of total extractives (ca. 7-19\%), found in the different morphological regions has incentivated the study of the composition of this fraction.

As part of a research project aiming to find new applications for the banana plants vegetal residues produced after the harvesting of fruits, we have been studying the chemical composition of the plant tissues from different morphological regions of "Dwarf Cavendish" (M. acuminata Colla var cavendish), from Madeira Island. In the present paper we report the identification of three steryl glucosides, isolated from the different morphological regions of the plant, in considerably high amounts, which might contribute to the valorisation of the residues of "Dwarf Cavendish" plantations.

\section{Experimental}

\subsection{Materials and methods}

Mature banana plants "Dwarf Cavendish", were randomly selected from a banana plantation in Funchal, Madeira Island. The banana plants were harvested and separated into five fractions corresponding to different morphological regions. The pseudo-stems were handly separated into leaf sheaths and floral stalk. The foliage was also separated in petioles/midrib and leaf blades. Rachis was collected in a Banana Cooperative. After separation, the samples were air dried during 2 weeks. All morphological parts were milled and sieved. The 40-60 mesh fraction was used for chemical analysis.

The powdered samples $(3 \times 20 \mathrm{~g})$ from different morphological regions of "Dwarf Cavendish" were
Soxhlet extracted with dichloromethane for $6 \mathrm{~h}$. The solvent was evaporated to dryness and the extracts were weighed. The results were expressed in percent of dry material.

Before GC-MS analysis, nearly $20 \mathrm{mg}$ of each dried extract were dissolved in $250 \mu$ l of pyridine and compounds containing hydroxyl and carboxyl groups were converted into trimethylsilyl (TMS) ethers and esters, respectively, by adding $250 \mu \mathrm{l}$ of bis(trimethylsilyl)trifluoroacetamide and $50 \mu \mathrm{l}$ of trimethylchlorosilane. After the mixture had stood at $70{ }^{\circ} \mathrm{C}$ for $30 \mathrm{~min}$, the derivatized extracts were analysed by GC-MS (Freire et al., 2002a, 2002b). Each sample was injected twice. GC-MS analysis were performed using a Trace Gas Chromatograph 2000 Series equipped with a Finnigan Trace MS mass spectrometer, using helium as carrier gas $(35 \mathrm{~cm} / \mathrm{s})$, equipped with DB-1 J\&W capillary column $(15 \mathrm{~m} \times 0.32 \mathrm{~mm}$ i.d., $0.25 \mu \mathrm{m}$ film thickness). The chromatographic conditions were as follows: initial temperature: $100^{\circ} \mathrm{C}$ for $3 \mathrm{~min}$; temperature rate: $5^{\circ} \mathrm{C} / \mathrm{min}$; final temperature: $340{ }^{\circ} \mathrm{C}$ for $12 \mathrm{~min}$; injector temperature: $320^{\circ} \mathrm{C}$; transfer-line temperature: $290^{\circ} \mathrm{C}$; split ratio: $1 / 100$ (Freire et al., 2002a, 2002b). Quantification of the analysed compounds was calculated as an average of the six $\mathrm{GC}-\mathrm{MS}$ runs of each fraction.

\section{Results and discussion}

The GC-MS analysis (Fig. 1) of the dichloromethane extracts of the different morphological regions has shown that they are composed mainly by long chain fatty acids, (including several $\alpha$ - and $\beta$-hydroxyfatty acids), long chain aliphatic alcohols and sterols (with $\beta$-sitosterol, followed by stigmasterol and campesterol as the major components). Minor amounts of aromatic acids, mono-glycerides and fatty acids steryl esters (namely cycloartenyl octadecanoate and 24-methylenecycloartenyl octadecanoate) were also detected in the extracts of all fractions. All these components were identified based on their characteristic retention times and fragmentation patterns (Freire et al., 2002a, 2002b).

However, the most abundant chromatographic peaks (Fig. 1) are eluted at long retention times (43.0-44.5 min). These peaks were identified as campesteryl 3- $\beta$-D-glucopyranoside $\mathbf{1}$, stigmasteryl 


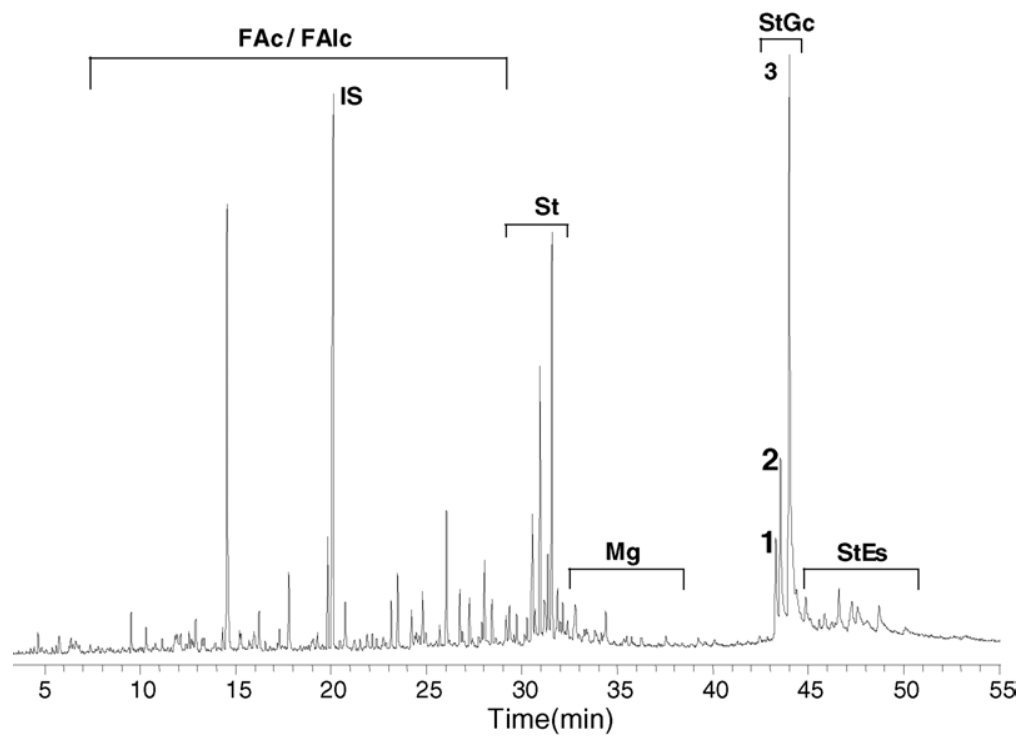

Fig. 1. GC-MS chromatogram of the dichloromethane extract of leaf blades from M. acuminata Colla var cavendish. FAc: fatty acids; FAlc: fatty alcohols; St: sterols; Mg: monoglicerides; StGc: steryl glucosides; StEs: steryl esters.

3- $\beta$-D-glucopyranoside $\mathbf{2}$ and sitosteryl 3- $\beta$-Dglucopyranoside 3 (Fig. 2). Their identification as TMS derivatives was based on their characteristic mass spectra and by comparison with literature data (Gutiérrez and del Río, 2001). The mass spectra (Fig. 3) of TMS derivatives of steryl glycosides, do not show the corresponding molecular ions, however their molecular weight can be determined indirectly based on the mass of [M-15], [M-15-90] and [M-15-90-90] ions. The loss of the sugar moiety (tetra-TMS) with charge retention on the sugar portion and cleavage of the glucose $\mathrm{C}-\mathrm{O}$ glycosidic bond, produces an ion at $\mathrm{m} / \mathrm{z}, 451$, which then loses trimethylsilanol producing a more intense peak at $\mathrm{m} / \mathrm{z} 361$. Furthermore, the high relative intensity of the fragment ion at $\mathrm{m} / \mathrm{z} 204$ (the base peak) and the lower abundance of that at $\mathrm{m} / \mathrm{z} 217$ is an indication of the hexose pyranoside configuration. Finally, the cleavage of the steryl $3-\mathrm{C}-\mathrm{O}$ bond with charge retention on the sterol moiety would produce intense ions with $\mathrm{m} / \mathrm{z}$ 383, 395 and 397 for steryl glucosides 1-3, respectively.

$\beta$-Sitosteryl glucoside was the most abundant component, followed by the stigmasteryl and campesteryl glucosides (Table 1). Compounds 1-3 account for $838.4-1824.3 \mathrm{mg} / \mathrm{kg}$ (reported to the vegetal fraction dry weight) of steryl glucosides in the different parts of banana plant. Though such high amounts of steryl glucosides were found in the vegetal parts of "Dwarf Cavendish" we have also checked their presence in the fruit pulp and peel in different maturation stages. The GC-MS analysis of the corresponding dichloromethane extracts revealed that steryl glucosides were only detected in minor amounts in the fruit pulp and peel. Although these type of compounds are ubiquitous in the plant kingdom (Grunwald and Huang, 1989), in most species they are found in small amounts.

Table 1

Steryl glucosides identified in M. acuminata Colla var cavendish ( $\mathrm{mg} / \mathrm{kg}$ of the vegetal fraction dry weight)

\begin{tabular}{llccccc}
\hline Peak & Compound & Petioles/midrib & Leaf blades & Floral stalk & Leaf sheaths & Rachis \\
\hline $\mathbf{1}$ & Campesteryl 3- $\beta$-D-glucopyranoside & 139.01 & 101.0 & 119.2 & 223.8 \\
$\mathbf{2}$ & Stigmasteryl 3- $\beta$-D-glucopyranoside & 352.1 & 208.9 & 263.3 & 624.1 & 106.4 \\
$\mathbf{3}$ & Sitosteryl 3- $\beta$-D-glucopyranoside & 1050.4 & 1350.5 & 678.8 & 976.4 & 490.8 \\
Total & & 1541.51 & 1660.4 & 1061.3 & 1824.3 & 838.4 \\
\hline
\end{tabular}




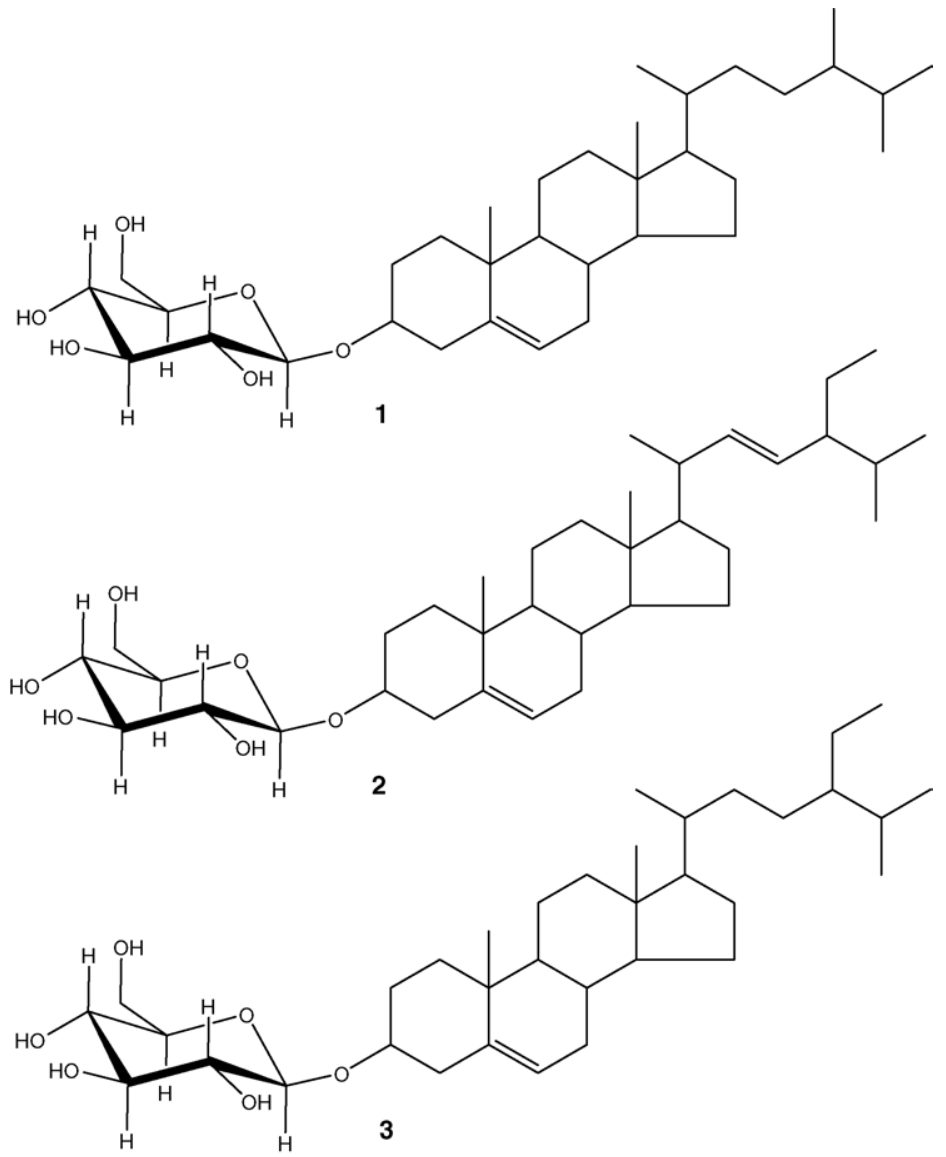

Fig. 2. Structures of the steryl glucosides 1-3 identified in different morphological fractions of M. acuminata Colla var cavendish.

In the case of banana species, they have already been reported in trace amounts in Musa paradisiaca $\mathrm{L}$. fruits (Ghoshal and Saini, 1984).

Steryl glucosides belong to the phytosterols family. These compounds have been intensively investigated during the last decades due to the wide variety of health benefits, (particularly their ability to lower blood cholesterol) associated with their inclusion in human diet (e.g. Moreau et al., 2002; Quílez et al., 2003). Furthermore, in recent years, steryl glucosides, and particularly the $\beta$-sitosteryl derivative, have deserved particular attention because of their specific properties. A wide number of pharmacological activities, such as: hepatoprotective (Banskota et al., 2000), antiinflammatory (Bouic et al., 1999; Delporte et al., 1998) among others, have been attributed to $\beta$-sitosteryl glucoside; however, its known anti-mutagenic and anti- cancer activities (Kiriakidis et al., 1997; Park et al., 2003), in general related to the consumption soy derived products, are probably the most relevant. Since there is an increasing market demand for functional foods enriched in phytosterols as complements of normal diets, the identification of new abundant vegetal sources of these compounds might be an important contribution to fill such demand and it will also contribute to the valorisation of such plants.

In conclusion, the results presented above demonstrate that M. acuminata Colla var cavendish vegetal parts can be a good source of steryl glucosides, particularly when they are expected to be used in functional foods. Such application can represent an important contribution to the valorisation of "Dwarf Cavendish" residues, and to increase the economical importance of banana plantations in Madeira Island. 

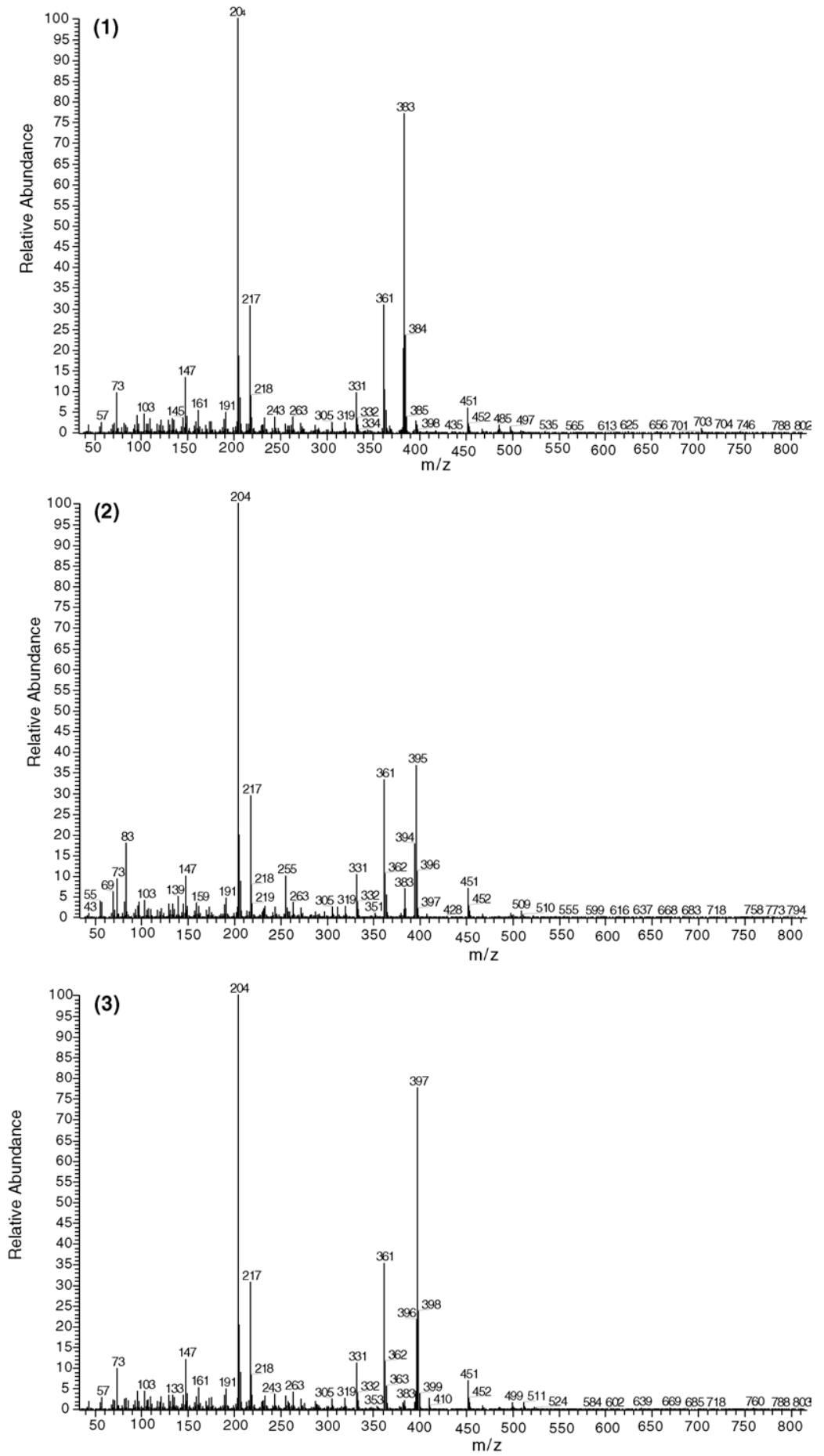

Fig. 3. Mass spectra of the steryl glucosides 1-3 (as TMS derivatives) identified in different morphological fractions of M. acuminata Colla var cavendish. 


\section{Acknowledgements}

Thanks are due to FCT for the awarding of a Ph.D. grant to L. Oliveira (SFRH/BD/4749/2001) and C. Freire (SFRH/BPD/11572/2002), to the "Cooperativa Agrícola dos Produtores da Madeira" for kindly providing the banana plant samples.

\section{References}

Banskota, A.H., Tesuka, Y., Adnyana, I.K., Xiong, Q.B., Hase, K., Tran, K.Q., Tanaka, K., Saiki, I., Kadota, S., 2000. Hepatoprotective effect of Combretum quadrangulare and its consituents. Biol. Pharm. Bull. 23, 456-460.

Bouic, P.J.D., Clark, A., Lamprecht, J., Freestone, M., Pool, E.J., Liebenberg, R.W., Kotze, D., Van Jaarsveld, P.P., 1999. The effects of $\beta$-sitosterol (BSS) and $\beta$-sitosterol glucoside (SSG) mixture on selected immune parameters of marathon runners: inhibition of post marathon immune supression and inflammation. Int. J. Sport Med. 20, 258262.

Cordeiro, N., Belgacem, M.N., Torres, I.C., Moura, J.V.C.P., 2004. Chemical composition and pulping of banana pseudo-stems. Ind. Crops Prod. 19, 147-154.

Delporte, C., Backhouse, N., Negrete, R., Salinas, P., Rivas, P., Cassels, B.K., San Feliciano, A., 1998. Antipyretic, hypothermic and anti-inflammatory activities and metabolites from Solanum ligustrinum Lood. Phytother. Res. 12, 118-122.

Faria, H., Oliveira, L., Cordeiro, N., Belgacem, M.N., 2002. "Dwarf Cavendish" as a source of natural fibres. Chemical modification and evaluation of process efficiency. International Congress in Production, Processing and Use of Natural Fibres. Potsdam, Berlin.

Freire, C.S.R., Silvestre, A.J.D., Pascoal Neto, C., 2002a. Identification of New Hydroxy Fatty Acids and Ferulic Acid Esters in the Wood of Eucalyptus globulus. Holzforschung 56, 143-149.
Freire, C.S.R., Silvestre, A.J.D., Pascoal Neto, C., 2002b. Lipophilic Extractives of the Inner and Outer Barks of Eucalyptus globulus. Holzforschung 56, 372-379.

Ghoshal, S., Saini, K.S., 1984. Sitoindosides I and II, two new antiulceragenic sterylacylglucosides from Musa paradisiaca. J. Chem. Res. (S), 110.

Grunwald, C., Huang, L.S., 1989. Analysis of sterylglucosides. In: Nes, W.D., Parish, E.J. (Eds.), Analysis of sterols and other biologically significant steroids. Academic Press, Inc., San Diego, pp. 49-60.

Gutiérrez, A., del Río, J.C., 2001. Gas chromatography/mass spectrometry demonstration of steryl glucosides in eucalypt wood, kraft pulp and process liquids. Rapid Commun. Mass Spec. 15, 2515-2520.

Kiriakidis, S., Stathi, S., Jha, H.C., Hartmann, R., Egge, H., 1997. Fatty acid esters of sitosterol 3-beta-glucoside from soybeans and tempe (fermented soybeans) as anti-proliferative substances. J. Clin. Biochem. Nutr. 22, 139-147.

Moreau, R., Whitaker, B.D., Hicks, K.B., 2002. Phytosterols, phytostanols and their conjugates in foods: structural diversity, quantitative analysis and health promoting uses. Progr. Lipid Res. 14, 457-500.

Nogueira, J.M.F., Fernandes, P.J.P., Nascimento, A.M.D., 2003. Composition of volatiles of banana cultivars from Madeira Island. Phytochem. Anal. 14, 87-90.

Oliveira, L., Cordeiro, N., Torres, I.C., Silvestre, A.J.D., 2002. Dwarf cavendish: chemical composition in different morphological regions-preliminary results. In: Proceedings of the 12th European Conference and Technology Exhibition on Biomass for Energy, Industry and Climate Protection, Amsterdam, pp. $1345-1347$.

Park, K.Y., Jung, K.O., Rhee, S.H., Choi, Y.H., 2003. Antimutagenic effects of doenjang (Korean fermented soypaste) and its active compounds. Mutat. Res. Fund. Mol. M. 523, 4353.

Quílez, J., Garcia-Lorda, P., Salas-Salvadó, J., 2003. Potential uses and benefits of phytosteros in diet: present situation and future directions. Clin. Nutr. 22, 343-351. 